\title{
Abordagens Somáticas em Dança: Uma outra Perspectiva em Pesquisa e Crianção ${ }^{1}$
}

Somatic Approach in Dance: Another Perspective in Research and Creation

Paloma Bianchi 


\section{Resumo}

As abordagens somáticas se encontram amplamente disseminadas nos processos pedagógicos das artes da cena, tanto por promoverem bem-estar e saúde corporal, como por fomentarem diferentes maneiras de aproximação do corpo e sua expressividade. No entanto, ainda persiste a convenção de que elas contribuem somente na preparação do corpo e no desenvolvimento da consciência corporal, negligenciando-se seu potencial como agente propositor e criador. Dessa maneira, se mantêm restritas a um papel apenas complementar nas práticas criativas das artes da cena. Explanando sobre sua função e problematizando a posição que ocupa nas práticas e vivências artísticas da atualidade, esse artigo visa ampliar e adensar o entendimento das abordagens somáticas, a fim de alargar os modos de aplicá-las nas artes da cena da contemporaneidade. Para tanto, propõe-se uma discussão entre os filósofos Merleau-Ponty e Michel Bernard sobre o conceito de corporeidade, articulando-a com a noção de ética de Spinoza.

Palavras-Chave: Abordagens somáticas; corporeidade; ética; criação.

\section{Abstract}

The somatic approaches are widely spread in the performing art's pedagogical processes, both by promoting physical wellbeing and health, as well as foster different ways to approach the body and its expressiveness. However, the convention that the somatic approaches only contribute in the physical conditioning and body awareness still remains, neglecting its potential as a proposer and creator agent. Thus, these approaches are restricted to a complementary role in the performing art's creative practices. Explaining its function and questioning the position it occupies in the artistic practices and experiences in the contemporaneity, this paper aims to widen and deepen the understanding of these approaches, in order to extend its applicabilities in the contemporary performing arts. For this propose, this paper proposes a discussion between philosophers Merleau-Ponty and Michel Bernard on the concept of corporeality, articulating it with the Spinoza's notion of ethics.

Keywords: Somatic approaches; corporeality; ethics; creation.

ISSN: $1808-3129$

\footnotetext{
1 Algumas reflexões contidas nesse artigo já foram parcialmente desenvolvidas pela autora num artigo escrito em parceria com a Professora Doutora Sandra Meyer Nunes, intitulado "A Coordenação Motora como Dispositivo para a Criação: uma abordagem somática na dança contemporânea", publicado no mês de dezembro de 2014 na edição especial sobre Educação Somática da Revista Brasileira de Estudos da Presença da Universidade Federal do Rio Grande do Sul.
}

${ }^{2}$ Mestranda em Teatro pelo Programa de Pós-Graduação em Teatro da UDESC - Universidade do Estado de Santa Catarina, Brasil; bianchi.paloma@gmail.com 
As artes da cena vêm se beneficiando desde meados do século $X X$ do encontro com as abordagens somáticas principalmente no campo da pedagogia, no qual vêm sendo empregadas amplamente com o intuito de preparar o corpo do ator e do bailarino para a ação em que o "fazer" e o "se perceber fazendo" não se desassociam. Essas abordagens possibilitam também diferentes formas de olhar para o corpo e sua expressividade, assim como agenciam novas maneiras de aproximação do movimento, muitas vezes contrastando com as técnicas tradicionais de dança como o ballet clássico, que privilegia a construção de corpos homogêneos. No entanto, sua disseminação no plano da criação ainda se mostra incipiente, talvez pela insistência no consenso de que elas exercem somente a função de cuidar do bem-estar e da restituição da saúde do corpo.

Evidentemente, tal consenso tem razão de ser, já que muitas dessas abordagens foram criadas por profissionais do campo das artes, principalmente da dança, que sofreram algum tipo de lesão que não podia ser curada satisfatoriamente pela medicina tradicional. Esses profissionais buscaram a cura a partir de experimentações e explorações de si mesmos, ou seja, foi na investigação profunda da propriocepção, a percepção de si, que encontraram meios de sanar suas lesões. A teorização e a estratificação de métodos surgem, assim, da própria experiência prática desses pesquisadores.

\section{As abordagens somáticas e alguns possíveis desdobramentos}

Na década de 1980, Thomas Hanna cunhou o termo Educação Somática com o intuito de reunir, em um só grupo, estudos que traziam em seu bojo modos de lidar com o corpo através da exploração e investigação de si, engajando, na ação, a percepção do ambiente e a propriocepção. Esses estudos partem do princípio de que o conhecimento não se constitui pela transmissão de informação de uma pessoa à outra, de um professor a um aluno: ao contrário, ele emerge da experiência da relação que a pessoa estabelece com si mesma e com seu entorno. Hanna (1986) substitui a palavra corpo por soma - por este incluir a percepção interna e externa em primeira pessoa $^{3}$-, mas eu sugiro a substituição da palavra educação por abordagem, por acreditar que educação remete a uma ideia mais tradicional e hierárquica de transmissão de saberes, enquanto abordagem indica modos mais horizontalizados de se aproximar da prática corporal, proporcionando uma fundamentação estruturada mas não rígida para a experimentação. O termo abordagem está mais ligado à ideia de apreender algo, captar e perceber, enquanto educação se vincula à ideia de aprender, adquirir, obter e memorizar. Abordagens somáticas, como a Eutonia, a Ideokinesis, o Feldenkrais, a técnica Alexander e o Body Mind Centering (BMC), têm como escopo o engajamento do corpo no processo de aprendizagem a fim de oferecer maior autonomia não só no reestabelecimento da saúde, mas também no modo da pessoa lidar com a própria experiência.

Nas últimas três décadas os termos soma e somático vêm se popularizando e

\footnotetext{
${ }^{3}$ Soma se diferencia de corpo pela questão do ponto de vista: é a propriocepção imediata e única através dos sentidos.
} 
consequentemente perdendo seu sentido original, passando a ser utilizados indiscriminadamente para definir qualquer técnica ou método que fuja de uma visão corporal mecanicista. Marcia Strazzacappa (2010) aponta que tais termos viraram um selo de garantia e de qualidade de todo e qualquer trabalho corporal. Lima (2010) inclui nessa discussão a postura profissional de professores das ditas técnicas de educação somática que simplesmente aplicam um conjunto de movimentos e um punhado de pensamentos esperando que isso seja suficiente para transformar o sujeito e sua relação com o mundo.

Lima (2010) designou alguns parâmetros ${ }^{4}$ que permitem circunscrever o campo de atuação das abordagens somáticas, dentre os quais destaco um: a modificação de padrões de movimentos estratificados, que transforma as relações que o sujeito estabelece com o mundo, alterando, assim, as formas de esse sujeito atuar sobre o mundo. Ao adensar seu entendimento, percebe-se que a reeducação postural e o reestabelecimento da saúde corporal são apenas alguns dos benefícios possíveis dessas abordagens, mas não os únicos: sua área de ação transborda sua função original e passa a ocupar outro território, um território mais próximo da fenomenologia. Aliás, não se pode deixar de notar a sincronia na emergência de alguns desses estudos também em termos de época: tanto a fenomenologia como algumas abordagens somáticas (como Feldenkrais, Eutonia e Técnica Alexander) nasceram nas primeiras décadas do século $X X$, momento histórico em que as discussões sobre o corpo ganharam grande evidência.

A relação de afetação recíproca entre corpo e ambiente apontada pelo filósofo francês Merleau-Ponty (1999) remonta à década de 1940. Em seu tratado sobre a percepção, longo e complexo, o filósofo indica que a constituição do sujeito não resulta, nem se determina, por causalidades: tudo que se é e tudo que se sabe sobre o mundo - ainda que seja por um exercício intelectual - se dá por meio da relação deste corpo com este mundo. Assim, cada visão, única e particular, surge a partir da experiência vivenciada pelo sujeito. Merleau-Ponty critica duramente qualquer abordagem que entenda o corpo separado do espírito, da experiência e da consciência, da mesma maneira que critica a ideia de intelectualidade apartada do que é vivenciado.

O filósofo (MERLEAU-PONTY, 1999) coloca a experiência como aquilo que permite conhecer a si e o mundo, destituindo a reflexão abstrata do lugar onipotente vigente em sua época. O corpo não é entendido com um mediador entre a subjetividade e o mundo, nem o conhecimento se dá por uma reflexão interiorizada e quase "desencarnada": é a experiência do sujeito em relação com o mundo que constitui a subjetividade, ou seja, sua corporeidade. O filósofo substitui interioridade por corporeidade ao colocar que é na comunicação com o mundo que se apoia todo e qualquer conhecimento e racionalidade. Dessa maneira, então, para o autor, corporeidades são modos, práticas de vivenciar o corpo; práticas pessoais, intransferíveis.

Merleau-Ponty (1999) não se ocupou da questão da incorporação dos modos e

4 Lima aponta quarto parâmetros: "(1) a defesa da individualidade do ser: corpo/espírito, alma/matéria, corpo/mente etc.; (2) a defesa de que as relações que o indivíduo mantém com o seu fazer no mundo podem criar situações que se fixariam sobre o comportamento psicomotor, impedindo seu adequado desempenho, cuja recuperação cada uma das técnicas propõem; (3) os co-

nhecimentos que dão suporte às teses são de caráter científico e fazem parte das ciências biológicas e humanas; (4) a defesa de que o desenvolvimento no indivíduo da consciência de seus próprios atos é instrumento de mudança de seu estar no mundo." (LIMA, 2010, p. 45) 
das práticas engendrados pela cultura, mas, seguindo sua linha de reflexão, muitos autores deram continuidade às observações da filosofia fenomenológica - assim, as ponderações do filósofo Michel Bernard a respeito do engendramento da cultura no corpo se mostram pertinentes para tal reflexão. Bernard (2001) pondera que o corpo se constitui, de forma processual, sob grande influência da cultura, moldando-se ininterruptamente em contato com o ambiente, numa ação recíproca. O filósofo também afirma que a visão de corpo vigente tem sua origem na tradição teórico-metafísica ocidental - uma visão técnico-científica capitalista normatizada - , fazendo-se indispensável seu questionamento.

Bernard (2001) problematiza até o vocábulo "corpo", que, segundo ele, carrega em si marcas, vestígios de conceitos e de ideias que podem falsear e deturpar os processos de constituição da nossa relação com nós mesmos e com o mundo, e aponta cinco reducionismos que operam essa falsificação: (1) a transformação do processo sensorial da percepção em um processo cognitivo de informação - que aparta a percepção da experiência encarnada; (2) a transformação do processo pulsional e energético da expressão em um processo de comunicação - a relação autoafetiva da expressão se transforma em emissão e transmissão; (3) a ação se torna utilitária e relacional em vez de carregada de intensidades e energia - nessa redução o corpo se torna suporte; (4) o pensamento se transforma em lógica organizacional - a racionalidade calculada usurpa a força inovadora e o imaginário; (5) a poética da palavra "corpo" dá lugar à hegemonia da semântica da transmissão da mensagem - o corpo se torna veículo da informação. Bernard conclui:

\footnotetext{
Nossa experiência cotidiana se encontra a priori in-formada e normalizada por um imaginário social e pelo discurso que este modelo engendra e promete. Como tentei mostrar no meu livro intitulado ironicamente "O corpo", nós não vivemos nossa relação conosco, com os outros e com o mundo senão através da nossa história por vezes coletiva e individual, cultural e pulsional. Assim, a categoria de "corpo" regula e governa, por suas implicações, a complexidade, a contingência e a fugacidade aparentes de nossa vivência mais banal. (BERNARD, 2001, p. 23)
}

As observações do filósofo apontam que o modo de operar da atualidade visa, acima de tudo, a produção e a manutenção de um sistema que aparta os indivíduos da experiência real e concreta de si, e, consequentemente, da sua experiência em relação com o mundo. A construção da subjetividade é falseada, o desejo é falseado, a experiência é descontinuada e desagregada de sentido. $O$ sentido de si é forjado por experiências prontas, pré-moldadas, normatizadas. A suspensão desse fluxo de experiências engendradas pelo "processo técnico-científico de um capitalismo triunfante" (BERNARD, 2001, p. 23) se evidencia indispensável.

Mas com o que as abordagens somáticas podem contribuir com a transformação no modo de operar do indivíduo? Hanna (1986) sugere que essas abordagens procuram remodelar e regular não só as funções volitivas - ações deliberadas, escolhidas - como também as funções involitivas - aquelas das quais o corpo, a princípio, não possui domínio consciente -, por meio da experimentação e da exploração consciente do sistema sensório-motor. Refinando a consciência (awareness), reconhecendo o sistema sensório-motor e exercitando-o voluntariamente, podem-se 
conquistar controle e domínio sobre ele - assim, aquilo que anteriormente se dava involuntariamente passa a ser voluntário; aquilo que era desconhecido torna-se conhecido; aquilo que nunca havia sido feito, ou que era impossível de fazer, torna-se possível e factível. A experimentação consciente, meticulosa e profunda do sistema sensório-motor faz emergir outros e novos repertórios corporais, novos modos de fazer e novos modos de se estar no mundo. Importante salientar que essas ações não buscam condicionar o corpo - como fazem a cultura, as relações de poder e o capitalismo; pelo contrário, procuram descondicioná-lo das respostas prontas e desvinculá-lo das ações automatizadas operadas no cotidiano, ativando uma percepção mais refinada. Não há diferença entre a forma, o funcionamento e o comportamento (FAVRE, 2011); descondicionando a forma, descondiciona-se o modo de operar, o modo de se perceber, da mesma forma que transforma-se o modo de se comportar. A experiência da propriocepção é uma maneira de captação de sentido de si mesmo. Investigando e experienciando - suas formas, seus modos, suas automações, suas relações com o ambiente -, o indivíduo reconhece a si e em si, abrindo uma brecha para outras possibilidades de se modelar, de se regular e de se reorganizar em seu estar no mundo, ampliando o leque de respostas aos acontecimentos.

\section{Problematizando o uso das abordagens somáticas nas artes da cena}

A pesquisadora Sylvie Fortin (1999) aponta que a dança poderia se beneficiar do encontro com as abordagens somáticas de três maneiras diversas: na melhora da qualidade técnica, na questão da prevenção de lesões e na ampliação da capacidade expressiva. Segundo a autora, o mercado de trabalho de dança hoje demanda corpos tecnicamente polivalentes e com grande capacidade de adaptação às exigências dos diretores de companhia ou coreógrafos: retornar ao gesto fundamental e desenvolver a aprendizagem a partir da própria estrutura corporal, como propõem as abordagens somáticas, pode ser um caminho vantajoso aos dançarinos que procuram construir corpos mais "neutros". Fortin também aponta que o trabalho meticuloso e consciente, proposto por essas abordagens, ajuda na questão da prevenção e cura de lesões, pois, ao fomentar o conhecimento da mecânica e da cinesiologia do gesto a partir da própria ação, assim como estimular o refinamento da propriocepção, aliando a percepção mecânica à percepção sensorial, o aprendizado se torna menos automatizado, permitindo que o bailarino aprenda meios de prevenir ou curar lesões.

O terceiro ponto elencado pela pesquisadora (FORTIN, 1999) recai sobre o aumento da capacidade expressiva do bailarino. O gesto se compõe de diferentes camadas - mecânica, psicológica, espiritual, social, emocional, cognitiva -, e não basta, portanto, ao corpo que dança executar perfeitamente um movimento, mas há de se ter consciência de todos esses atravessamentos. Fortin sugere que as abordagens somáticas seriam um caminho mais direto e concreto para lidar com os atravessamentos, pois elas buscam uma "reorganização global da experiência" (1999, p. 44).

Os três benefícios apontados por Fortin, há cerca de vinte anos, foram e são substancialmente reproduzidos desde então no universo acadêmico - em diferen- 
tes artigos, teses e dissertações -, como também balizaram a maneira pela qual as abordagens somáticas são incluídas nas práticas da dança. Suas afirmações, ainda que absolutamente coerentes, tornaram-se referência no modo de pensar a relação entre essas duas áreas e acabaram por restringir as abordagens somáticas ao campo pedagógico, ao processo de aprendizagem da dança, sendo pouco exploradas nos processos criativos e artísticos.

Diferentes abordagens somáticas fazem parte da grade de disciplinas de grande parte das graduações e pós-graduações das artes cênicas. Na França, a graduação em licenciatura em dança abarca não somente aulas de técnicas de dança, como o ballet e o jazz, como também aulas de anatomia, fisiologia e cinesiologia, o que nesse país chama-se análise funcional do movimento dançado, correspondente ao que comumente chamamos de Educação Somática (SOTER, 1999). O mesmo pode ser observado no Brasil. Por exemplo, na graduação de Comunicação nas Artes do Corpo da PUC de São Paulo, disciplinas como Eutonia e Cinesiologia também fazem parte da formação dos artistas do corpo. Em São Paulo, também existe a pós-graduação em Educação Somática da Faculdade Anhembi-Morumbi e, no Rio de Janeiro, a pós-graduação no método Angel Vianna, só para citar algumas. As abordagens somáticas aqui apresentadas estão em função de complementaridade e são utilizadas como suporte aos processos pedagógicos.

Percebe-se que, na atualidade, diferentes tipos de abordagens somáticas estão amplamente disseminadas nas escolas, graduações de bacharelado e de licenciatura e pós-graduações de todo o País. O mesmo não pode ser observado em relação à utilização dessas abordagens como parte de processos criativos e artísticos. Mesmo que muito processos em dança se iniciem a partir da experiência do corpo, não é comum encontrar pesquisa em criação que principie com alguma abordagem somática. Ainda que existam tais aproximações, elas, muitas vezes, permanecem limitadas ao campo que Fortin (1999) apontou em 1996 - na preparação e no treinamento corporal -, não sendo incluídas como parte do processo de criação.

Rompendo tal regra, embora de maneira esparsa, existem experiências que criam diálogos entre criação e experimentação somática, por exemplo, no trabalho de Marila Velloso5 5 . Essa artista, professora e pesquisadora paranaense pesquisa há muitos anos Body Mind Centering ${ }^{6}$, aplicando-o tanto em suas práticas pedagógicas como em seus processos de criação. No espetáculo Ditado no Escuro7 , a criação partiu da pesquisa de dois sistemas do BMC: o sistema esquelético - trabalhando a questão da estrutura e, a partir disso, se relacionando com as questões da infância - e o sistema orgânico - trabalhando a ideia de água e de ancestralidade, questões que também faziam parte do tema do espetáculo em questão.

Semelhantemente a Velloso, Cinthia Kunifas ${ }^{8}$ (2008) aponta que as abordagens somáticas abriram novas possibilidades no processo de criação de seu solo Cor-

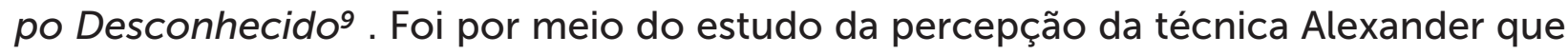

5 Marila Velloso é dançarina, professora de dança da Faculdade de Artes do

Paraná e pesquisadora de dramaturgia em dança.

6 Body Mind Centering é um sistema de preparo corporal criado por Bonnie Bainbridge Cohen, comumente chamado de BMC

70 espetáculo Ditando no Escuro pode ser assistido na íntegra neste link: https://www.youtube.com/watch?v=hdJQr4QZj-8. Acesso em: 05 out. 2014.

8 Cinthia Kunifas é professora da Faculdade de Artes do Paraná. Também é bailarina e preparadora corporal.

9 Nessa entrevista com Cinthia Kunifas, a artista fala sobre seus processos criativos: http://www.youtube.com/watch?v=pluYXZEb-v4. Acesso em: 05 out. 2014.

Body Mind Centering é um sistema de preparo corporal criado por Bonnie Bainbridge Cohen, comumente chamado de BMC

O espetáculo Ditando no Escuro pode ser assistido na íntegra neste link: https://www.youtube.com/watch?v=hdJQr4QZj-8. Acesso em: 05 out. 2014. Cinthia Kunifas é professora da Faculdade de Artes do Paraná. Também é bailarina e preparadora corporal. 
a bailarina voltou seu olhar para o corpo que dança, em vez de focar sua atenção no próprio movimento. O tema desse espetáculo é a experiência do corpo em si, não há uma ideia anterior a ser trabalhada, o que existe é uma pesquisa sobre a atenção em si, no instante; o corpo é a própria matéria, tema e assunto. Nesse solo, a bailarina investiga sua relação com o ambiente e trabalha sobre as emergências de cada instante: as micropercepções e os atravessamentos singulares que ocorrem no espaço-tempo.

Mesmo que o resultado de cada uma dessas artistas seja absolutamente diverso, há um denominador comum: ambas estão interessadas na potência de cada indivíduo, qual é a dança que cada sujeito viabiliza? qual é a dança que essa pessoa cria? Não procuram impor e submeter o corpo do intérprete a uma fórmula preestabelecida, ou a uma técnica rígida; ao contrário, procuram encontrar o que há de singular em cada gesto de cada pessoa, aquilo que há de único, o modo intransferível de ser, agir, dançar e criar de cada um. Mais que isso, estão interessadas nas potencialidades de afeto de cada corpo, em descobrir o que pode "esse" corpo quando posto em relação, em formas de tornar o corpo cada vez mais poroso, suscetível e disponível para que os possíveis atravessamentos, que possam vir a emergir do ambiente, a cada instante, contagiem o gesto. O trabalho sobre as corporeidades não é mais voltado para a compreensão de algo sobre si ou sobre o mundo, mas para facilitar a emergência de potência.

O discurso sobre corporeidade mais vigente nas abordagens somáticas se encontra ligado às reflexões da filosofia de percepção dos filósofos Merleau-Ponty e Husserl. Na concepção desses filósofos, corporeidade é uma maneira de "designar a modalidade concreta ou sensorial do processo cognitivo" (BERNARD, 2001, p. 25), ou seja, o sentido de algo, quer seja uma paisagem, quer seja um estado, se encontraria preenchido por uma percepção cujo objetivo último é a compreensão ou o entendimento de algo. Assim, parece lógico vincular as abordagens somáticas aos processos pedagógicos, já que estes, acima de tudo, visam o aprendizado de algo.

Mas se seu entendimento for expandido, e passarmos, como sugere Bernard (2001), a compreender corporeidade como algo mais amplo, menos ligado a uma intencionalidade de compreensão ou entendimento, e muito mais conectado à ideia de uma estrutura, ou uma trama, que sustenta a sensorialidade e a materialidade - e a maleabilidade inerente a elas -, como um "entrelaçamento polissensorial" (BERNARD, 2001, p. 26), possivelmente poder-se-á ter outro modo de entender o papel da corporeidade nas abordagens somáticas. Sob essa outra ótica, o objetivo não é aprender algo, mas apreender o que existe em estado de potência. Ao se vincular as práticas e reflexões dessas abordagens ao conceito de corporeidade proposto por Bernard (2011), um outro terreno de exploração pode ser gerado: um terreno que não busca compreender algo, ou entender algo, mas simplesmente procura maneiras de lidar com as corporeidades emergentes, com os devires de corpo e com os possíveis corpos que podem vir a eclodir a partir da percepção de si no ambiente, sem haver a necessidade de nomeá-los, dar-lhes formas estratificadas ou estruturar uma outra fórmula de funcionamento. 


\section{As abordagens somáticas na pesquisa em arte}

Seguindo sua reflexão sobre o espaço que o corpo ocupa na sociedade da atualidade, Bernard (2001) sugere que as artes da contemporaneidade tiveram papel preponderante no desmonte da visão técnico-científica hegemônica e na desconstrução dos modelos corporais vigentes:

[...] o surgimento da Arte Contemporânea - e, mais particularmente, a profunda reviravolta que ela introduziu na compreensão do processo de criação - contribuiu para desconstruir este modelo, recolocando em questão sua hegemonia. Inspirados, estimulados e encorajados pela visão ou pelas reflexões de artistas como Cézanne, Artaud, Klee, Kandinsky, Bacon ou Cage, e numerosos pensadores também diferentes, visões divergentes, que Merleau-Ponty, Ehrenzweig ou Deleuze, nos revelam que o ato criador não é feito do poder inerente a um "corpo" como estrutura orgânica permanente e significante. Bem ao contrário, tal ato resulta do trabalho de uma rede material e energética móvel, instável, de forças pulsionais e de interferências de intensidades díspares e cruzadas. [...] O psicanalista austríaco Anton Ehrenzweig, autor de L'Ordre caché de l'art, afirma que todo ato de criação se efetua por um rastreamento [scanning] ou varredura inconsciente de estruturas que a consciência percebe na superfície como desconectadas, o que implica o uso de um modelo de corpo não mais substancialista e permanente, mas reticular e móvel. Concebido como um espectro sensorial, heterogêneo e contingente, este corpo é trabalhado por um duplo mecanismo antinômico de diferenciação e de desdiferenciação (isto o que Ehrenzweig nomeia de serialisação). Melhor dito, longe de ser a emanação de um corpo-sujeito homogêneo e idêntico, a produção artística é uma desconstrução e descoberta de sua materialidade sensível instável e aleatória. (BERNARD, 2001, p. 19-20)

Tal perspectiva transforma o status da arte: de um entendimento de arte como uma atividade autônoma transcendente para o entendimento de arte como um devir de intensidades que transita entre a diferenciação e a conjunção, e entre a distorção e o agenciamento. Seu sentido nunca é fechado, único e estratificado, mas sempre polifônico, precário, suscetível a variações, nômade por natureza. Ao artista cabe o papel de viajante errante de um caminho labiríntico, ou seja, o artista, nesse contexto, é aquele que possui a potência de modular suas intensidades a fim de articular sentidos nesse emaranhado perpétuo de potências de vir a ser. Assim, lhes são exigidas habilidades específicas, como viabilizar e sustentar um corpo capaz de lidar com as micropercepções, as pequenas diferenciações e as distorções emergentes que afetam e alteram seu próprio estar no mundo e seu modo de agir sobre esse mundo; um corpo completamente diverso daquele corpo técnico, morfológico, coeso, significante e isolado.

Para tanto, Bernard (2001) afirma que se torna imprescindível a instituição de uma outra relação pedagógica que propicie um modelo de corpo menos substancialista, que não seja vinculado à transmissão de informação ou a um processo de comunicação linear de significado. Uma nova relação pedagógica que permita ao corpo lidar com as incertezas e "com as contingências de uma vivência relacional, e, portanto, da temporalidade de uma experiência" (BERNARD, 2001, p. 24). As abordagens somáticas já possuem esse papel na pedagogia; porém, como transpor tal prática ao processo de criação? Talvez a primeira ação seja ampliar o entendimento sobre o 
modo de atuação desses processos, e, como consequência, observar sua imbricação nas construções de poéticas.

As abordagens somáticas possuem modos de fazer e agir, conectados aos processos perceptivos e sensíveis da experiência de cada indivíduo no espaço-tempo em sua relação com o mundo. Mais do que oferecer respostas, essas abordagens propõem questionar os modos de manejo de si e os modos de agir do corpo. Partindo dessas premissas, pode-se considerar, então, que elas atuam sobre a ética. Para Deleuze (1978), seguindo as reflexões propostas por Bento Spinoza, ética é a ciência prática que investiga os modos de existência imanentes, particulares a cada indivíduo, não maneiras gerais que abarcam a humanidade como um todo, mas aquilo que constrói e estrutura a ação de cada sujeito sobre o mundo, as potencialidades e as capacidades intransferíveis de cada sujeito. Ética não é um problema de dever, nem está ligada ao desejo ou à vontade, é uma questão de potência de afetos - quanto um corpo pode ser afetado -, por isso se encontra circunscrita nas perguntas: do que é capaz um corpo? o que pode "esse" corpo em particular? o que posso? do que sou capaz? o que faço?

Eleonora Fabião (2008) afirma que o corpo "tem o poder de afetar e ser afetado" (FABIÃO, 2008, p. 238) e que tal capacidade delineia as singularidades de cada corpo: o que e como ele afeta, pelo que se afeta e como é afetado. Transportando essa ideia de corpo em processo para o trabalho do artista cênico, a pesquisadora aponta:

O corpo cênico está cuidadosamente atento a si, ao outro, ao meio; é o corpo da sensorialidade aberta e conectiva. A atenção permite que o macro e o mínimo, grandezas que geralmente escapam na lida quotidiana, possam ser adentrados e explorados. Essa operação psicofísica, ética e poética desconstrói hábitos. [...] A atenção é uma forma de conexão sensorial e perceptiva, uma via de expansão psicofísica sem dispersão, uma forma de conhecimento. A atenção torna-se assim uma pré-condição da ação cênica; uma espécie de estado de alerta distensionado ou tensão relaxada que se experimenta quando os pés estão firmes no chão, enraizados de tal modo que o corpo pode expandir-se ao extremo sem se esvair. (FABIÃO, 2010, p. 322)

Nas artes da cena, o modo de ser e sua potência de ação desencadeiam o modo de fazer: a ética se vincula à poética - do grego poiein, fazer, gerar. Louppe (2012) designa poética como o campo operativo que abrange o saber, os afetos e as ações, ou seja, a ponte que permite a experiência e a percepção da arte. Afirma ainda que, na dança, a poética toma contornos muito mais intensos que em outras formas de arte, como por exemplo a literatura - em que um instrumento substitui a presença concreta -, já que nessa forma de arte o sujeito está implicado corporalmente no fazer. A poética na dança é a própria ação - incorporada, vivida, vivenciada e expressa -, sem mediação; o próprio corpo produzindo a partir de sua matéria. Sob tal perspectiva, o modo de fazer - a ética - já é a própria poética. Segundo a autora, tal produção não é aleatória, há alguns valores comuns identificáveis que permeiam grande parte do fazer artístico na dança contemporânea: 
A individuação de um corpo e de um gesto sem modelo que exprime uma identidade ou um projeto insubstituível, a produção (e não a reprodução) de um gesto (a partir da esfera sensível individual - ou de uma adesão profunda e cara aos princípios de um outro), o trabalho sobre a materialidade do corpo e do indivíduo (de maneira subjetiva ou, pelo contrário, em ação de alteridade), a não antecipação sobre a forma (ainda que os planos coreográficos possam ser traçados de antemão) e a importância da gravidade como impulso do movimento (quer se trate de jogar com ela ou de se abandonar a ela). Em causa estão também valores morais como a autenticidade pessoal, o respeito pelo corpo do outro, o princípio da não-arrogância, a exigência de uma solução justa, e não somente espetacular, a transparência e o respeito por diligências e processos empreendidos (LOUPPE, 2012, p. 45)

Os elementos apontados por Louppe (2012) não são estranhos às abordagens somáticas; pelo contrário, esse é justamente seu campo de ação: a investigação da própria materialidade do corpo a fim de provocar um constante estado de devir; um corpo atento aos atravessamentos potenciais do ambiente, a fim de produzir (e não reproduzir) um gesto particular, exclusivo e não automatizado. Como disseram Lima (2010) e Hanna (1986), as abordagens somáticas lidam com a transformação da percepção do corpo em si: sentir, reconhecer, experimentar outras formas a fim de alargar e ampliar as potencialidades de afeto e diversificar os modos de se estar e de agir sobre o mundo.

$\mathrm{Na}$ contemporaneidade, o artista detém a função de problematizar a existência criando modos de resistir e reexistir num mundo onde a percepção se encontra cerceada e moldada por um sistema que investe na manutenção de experiências falseadas, forjadas e normatizadas (BERNARD, 2001). Para tanto, ele necessita adquirir meios de agenciar sua sensorialidade, manejar intensidades e potencializar a emergência de estados a fim de tocar, sensibilizar e afetar o outro. Se as abordagens somáticas oferecem maneiras de desestabilizar a percepção e propiciam modos não ordinários de se estar em si, diversificando e dilatando os estados de presença, para, assim, ampliar a potência de afeto do artista, tecer relações entre processos investigativos e abordagens somáticas pode ser uma ação fértil na criação nas artes da cena.

No entanto, para que as abordagens somáticas passem a operar no processo de criação nas artes da cena, faz-se necessário expandir sua compreensão: deslocá-las do campo da manutenção da saúde do corpo e passar a entendê-las como dispositivo de agenciamento perceptivo. Uma vez tomada essa opção mais abrangente, há de se elaborar estratégias compositivas entre elas e outros gêneros artísticos, conceitos e ideias, a fim de complexificar o processo criativo. Também há de se articular os conteúdos advindos das experimentações com as abordagens somáticas junto às questões emergentes do mundo. As práticas pelas práticas não se sustentam sozinhas, é preciso buscar o encontro, a relação, para que seja possível a partilha do sensivel. 


\section{Referências Bibliográficas}

BERNARD, Michel. De la corporeité comme "anticorps" tradução não publicada. De la création choréographique. Tradução Marta César. Paris: Centre National de la danse, p. 17-25, 2001.

DELEUZE, Gilles. Gilles Deleuze - Curso sobre Spinoza, 1978. Disponível em: <http://reflexionesmarginales.com/3.0/17-pdf/gilles-deleuze-curso-sobre-spinoza/>. Acesso em: 24 ago. 2014.

FABIÃO, Eleonora. Corpo cênico, estado cênico. Revista Contrapontos , v. 10, n. 3, p. 321-326, 2010.

FABIÃO, Eleonora. Performance e teatro: poéticas e políticas da cena contemporânea. Sala Preta, v. 8, p. 235-246, 2008. Acesso em: 24 ago. 2014.

FAVRE, Regina. Um corpo na multidão: do molecular ao vivido. .Laboratório do Processo Formativo, 2011. Disponível em: <http://laboratoriodoprocessoformativo. com/2011/11/um-corpo-na-multidaodo-molecular-ao-vivido/>. Acesso em: 23 ago. 2014.

FORTIN, Sylvie. Educação somática: novo ingrediente da formação prática em dança. Cadernos do GIPE-CIT: Grupo Interdisciplinar de Pesquisa e Extensão em Contemporaneidade, Imaginário e Teatralidade. Salvador: UFBA, p. 40-55, 1999.

HANNA, Thomas. What is Somatics? Somatics: Magazine-Journal of the Bodily Arts and Sciences, v. 5, n. 4, p. 4-8, 1986.

LIMA, José Antonio de Oliveira. Educação somática: diálogos entre educação, saúde e arte no contexto da proposta da reorganização postural dinâmica. tese (Doutorado em Educação) - Programa de Pós-Graduação em Educação/UNICAMP, Campinas, 2010.

LOUPPE, Laurence. Poéticas da dança contemporânea. Tradução Rute Costa. Lisboa: Orfeu Negro, 2012.

MERLEAU-PONTY, Maurice. Fenomenologia da percepção. Tradução Carlos Alberto Ribeiro De Moura. 2. ed. São Paulo: Martins Fontes, 1999.

SOTER, Silvia. A educação somática e o ensino da dança. In: SOTER, Silvia; PEREIRA, Roberto (Orgs.). Lições de dança 1. Rio de Janeiro: UniverCidade Editora, 1999.

STRAZZACAPPA, Marcia. Educação Somática: seus princípios e possíveis desdobramentos. REPERTÓRIO: Teatro \& Dança, n. 13, p. 48-54, 2010. Acesso em: 7 ago. 2014. 